\title{
EDITORIAL
}

\section{Intensive care during the coronavirus epidemic}

\author{
Haibo Qiu' ${ }^{1}$ Z Zhaohui Tong ${ }^{2}$, Penglin $\mathrm{Ma}^{3}$, Ming Hu${ }^{4}$, Zhiyong Peng ${ }^{5}$, Wenjuan $\mathrm{Wu}^{6}$ and Bin $\mathrm{Du}^{7 *}$ (D) on behalf of \\ China Critical Care Clinical Trials Group (CCCCTG)
}

๑ 2020 Springer-Verlag GmbH Germany, part of Springer Nature

In late December 2019, a cluster of patients with pneumonia of unknown cause was reported to local healthcare authorities, while a novel coronavirus (SARS-CoV-2) was identified as the etiology [1-3]. As of February 4, 2020, 20,471 confirmed cases, including 2788 severe cases and 425 deaths, were reported in China [4].

As a response to the epidemic, the local government had appointed several designated hospitals for patients with SARS-CoV-2 infection. Despite a common coping strategy for mass casualty (earthquake and blast injury) in China, SARI epidemic has proposed a new challenge for healthcare workers, especially intensivists. About $15-20 \%$ of suspected and confirmed patients with SARS-CoV-2 infection in fever clinics developed severe hypoxemia (since the second week of disease course), and required some form of ventilatory support such as high-flow nasal cannula, and non-invasive and invasive mechanical ventilation. In addition, other complications might occur, including, but not limited to, shock, acute kidney injury, gastrointestinal bleeding, and rhabdomyolysis. No antiviral agents have been proven to be effective against the coronavirus. Therefore, management of critically ill patients with SARS-CoV-2 infection still remains supportive rather than definitive, indicating remarkable workload for intensive care physicians and nurses. This surge of critically ill patients in designated hospitals as well as fever clinics represents urgent demands for intensive care with regards to space, supplies, and staff (Table 1) [5-8]. Response to these demands requires cooperation between the medical rescue team, infection

\footnotetext{
${ }^{*}$ Correspondence: Dubin98@gmail.com

${ }^{7}$ Medical ICU, Peking Union Medical College Hospital, 1 Shuai Fu Yuan, Beijing 100730, China

Full author information is available at the end of the article
}

Haibo Qiu and Zhaohui Tong contributed to the work equally. control specialists, local health authorities, and center for disease control and prevention [9].

Another important strategy is the centralization of critically ill patients with SARS-CoV-2 infection, i.e., transfer of patients requiring intensive care unit (ICU) admission into some designated hospitals with adequate specialist services. Potential benefits of centralized provision of intensive care might include better and more efficient utilization of scarce resources, and improved clinical outcome [10]. However, these benefits should be balanced against the risk of inter-hospital transfer, delay in access to intensive care, and de-skilling of staff in other designated hospitals [10]. In addition, intensivists are also involved in the inter-hospital transfer such as design of transfer plan, patient screening and evaluation, and escort of patients.

Like any natural disasters, epidemics, or other kinds of mass casualties, local healthcare capacity became overwhelmed by the COVID-19 epidemic, which necessitated a request for external assistance at the national level [11]. As part of the national response to inadequate local intensive care resources, 31 deployed support medical teams including 598 intensivists and 2319 ICU nurses from other cities have been dispatched to ICUs of the designated hospitals since early January 2020. However, it is not uncommon for them to spend some time to get familiar with colleagues, environment, and local hospital administration before working as a team. Furthermore, different personal experience and lack of knowledge of this novel disease often result in different, and sometimes conflicting, treatment plans within the same team. Therefore, a national intensive care expert team has been developed, with some experts working in ICUs as attendings, while other more senior experts make regular inspections of all hospitals and fever clinics with critically ill patients

\section{Springer}


Table 1 Demand for emergency mass critical care and possible solutions in designated hospitals during SARI epidemic

\begin{tabular}{|c|c|c|c|}
\hline & Demands & Difficulties & Potential solutions \\
\hline Space & $\begin{array}{l}\text { Double or triple ICU beds to cope with the } \\
\text { surge of critically ill patients requiring } \\
\text { mechanical ventilation and other sup- } \\
\text { portive care }\end{array}$ & $\begin{array}{l}\text { Limited physical space with specific func- } \\
\text { tionalities such as electricity, medical gas, } \\
\text { and suction } \\
\text { Not designed for infectious diseases spread- } \\
\text { ing via respiratory droplets or contact }\end{array}$ & $\begin{array}{l}\text { Post-anesthesia care unit and ED as primary } \\
\text { backup space } \\
\text { General wards with adequately ventilated } \\
\text { rooms as secondary backup space after } \\
\text { remodeling } \\
\text { Infection prevention and control measures } \\
\text { designed by infection control professionals }\end{array}$ \\
\hline Supplies & $\begin{array}{l}\text { Bedside monitors, ventilators, CRRT machine, } \\
\text { ECMO, portable X-ray equipment } \\
\text { PPE, such as N95 mask, googles, face shields, } \\
\text { long-sleeved gowns, and gloves }\end{array}$ & $\begin{array}{l}\text { Information about epidemic less predictable } \\
\text { during the initial phase } \\
\text { Information about patient characteristics } \\
\text { unavailable during the initial phase }\end{array}$ & $\begin{array}{l}\text { Provision of update and predicted estimates of } \\
\text { the epidemic by public health authorities } \\
\text { List of PPE and medical devices/equipment for } \\
\text { stockpiling } \\
\text { Prediction of supply based on patient volume, } \\
\text { staffing, and real-time consumption of PPE }\end{array}$ \\
\hline Staff & $\begin{array}{l}\text { Staffing of the medical rescue team, includ- } \\
\text { ing intensivists, intensive care nurses, and } \\
\text { respiratory therapists }\end{array}$ & $\begin{array}{l}\text { Lack of knowledge about infection control } \\
\text { and prevention } \\
\text { Heavy workload and associated risk of } \\
\text { contamination } \\
\text { Burnout }\end{array}$ & $\begin{array}{l}\text { Training provided by infection control profes- } \\
\text { sionals } \\
\text { Duration of every shift no longer than } 6-8 \mathrm{~h} \\
\text { Preparation of reserve medical rescue team for } \\
\text { substitution } \\
\text { Psychological consultation for healthcare } \\
\text { workers }\end{array}$ \\
\hline
\end{tabular}

CRRT continuous renal replacement therapy, ECMO extracorporeal membrane oxygenation, ICU intensive care unit, $P P E$ personal protection equipment, $S A R I$ severe acute respiratory infection

with SARS-CoV-2 infection, providing consultation for some difficult cases, discussing strengths and weaknesses of the patient management strategy, and providing suggestions to the national and local health authorities. In addition, the volume of critically ill patients with SARSCoV-2 infection has surpassed the intensive care supply for quite a long period of time, meaning that only a small proportion of critically ill patients could get access to intensive care services. Under these circumstances, patient triage and provision of essential rather than limitless intensive care would be very important [7].

Last, but not least, the COVID-19 epidemic has provided clinicians an opportunity to answer some important questions: is lopinavir/ritonavir or remdesivir effective against the SARS-Cov-2 infection? Does corticosteroid therapy improve lung injury in viral pneumonia? What is the effect of immune checkpoint inhibitors or thymosin in immunosuppression induced by the SARS-CoV-2 infection? There are some ongoing clinical trials in Wuhan and other cities in China, and we hope that results from these studies will help us to fight against the COVID-19 epidemic and other viral infections.

\footnotetext{
Author details

1 Department of Critical Care Medicine, Zhongda Hospital, Southeast University, Nanjing, Jiangsu, China. ${ }^{2}$ Department of Pulmonary and Critical Care Medicine, Beijing Chaoyang Hospital, Capital Medical University, Beijing, China. ${ }^{3}$ Department of Critical Care Medicine, Peking University Third Hospital, Beijing, China. ${ }^{4}$ Department of Critical Care Medicine, Wuhan Pulmonary Hospital, Wuhan, Hubei, China. ${ }^{5}$ Department of Critical Care Medicine, Zhongnan Hospital, Wuhan University, Wuhan, Hubei, China. ${ }^{6}$ Department of Critical
}

Care Medicine, Wuhan Jinyintan Hospital, Wuhan, Hubei, China. ${ }^{7}$ Medical ICU, Peking Union Medical College Hospital, 1 Shuai Fu Yuan, Beijing 100730, China.

\section{Acknowledgement}

This study was supported, in part, by the research Grant 2020 YFC0841300 from Ministry of Science and Technology of the People's Republic of China.

\section{Compliance with ethical standards}

Conflicts of interest

All authors report no conflicts of interest to declare.

\section{Publisher's Note}

Springer Nature remains neutral with regard to jurisdictional claims in published maps and institutional affiliations.

Received: 6 February 2020 Accepted: 10 February 2020 Published online: 20 February 2020

\section{References}

1. Zhu N, Zhang D, Wang W et al (2020) A novel coronavirus from patients with pneumonia in China, 2019. N Engl J Med. https://doi.org/10.1056/ NEJMoa2001017

2. Huang C, Wang Y, Li X et al (2020) Clinical features of patients infected with 2019 novel coronavirus in Wuhan, China. Lancet 395(10223):497-506

3. Chen N, Zhou M, Dong X, et al (2020) Epidemiological and clinical characteristics of 99 cases of 2019 novel coronavirus pneumonia in Wuhan, China: a descriptive study. Lancet 395(10223):507-513

4. World Health Organization. Novel coronavirus (2019-nCoV) Situation report-15, 4 February 2020. Available at. https://www.who.int/docs/ default-source/coronaviruse/situation-reports/20200204-sitrep-15-ncov. pdf?sfvrsn=88fe8ad6_2. Accessed 5 February 2020

5. Devereaux A, Christian MD, Dichter JR et al (2008) Summary of suggestions from the task force for mass critical care summit meeting, January 26-27, 2007. Chest 133:1S-7S

6. Christian MD, Devereaux AV, Dichter JR et al (2008) Definitive care for the critically ill during a disaster: current capabilities and limitations. From a 
task force for mass critical care summit meeting, January 26-27, 2007, Chicago IL. Chest 133:8S-17S

7. Rubinson L, Hick JL, Hanfling DG et al (2008) Definitive care for the critically ill during a disaster: a framework for optimizing critical care surge capacity. from a task force for mass critical care summit meeting, January 26-27, 2007, Chicago IL. Chest 133:18S-31S

8. World Health Organization. Infection prevention and control during health care when novel coronavirus (nCoV) infection is suspected. Interim guidance 25 January 2020. Available at. https://apps.who.int/iris/ rest/bitstreams/1266296/retrieve. Accessed 5 February 2020
9. Liao X, Wang B, Kang Y (2020) Novel coronavirus infection during the 2019-2020 epidemic: preparing intensive care units-the experience in Sichuan Province, China. Intens Care Med. https://doi.org/10.1007/s0013 4-020-05954-2

10. Ostermann M, Vincent JL (2019) How much centralization of critical care services in the era of telemedicine? Crit Care 23:423

11. Du B, Xi X, Kang Y et al (2009) Natural disaster. In: Gullo A, Besso J, Lumb PD, Williams GF (eds) Intensive and critical care medicine. Springer, Milan, pp 379-390 